\title{
Evolutionary Profile of Graves' Disease in Children at Albert Royer National Children Hospital in Dakar
}

\author{
Babacar Niang1*, Lamine Thiam², Fatou Ly³, Indou Dème Ly¹, Djibril Boiro ${ }^{4}$, Amadou Sow 4 , \\ Aliou Thiongane ${ }^{1}$, Aliou Abdoulaye Ndongo ${ }^{5}$, Aminata Mbaye ${ }^{1}$, Younoussa Keita ${ }^{5}$, Abou Ba$^{1}$, \\ Idrissa Demba Ba1, Yaay Joor Dieng1, Dienaba Fafa Cissé ${ }^{3}$, Papa Matar Faye1, \\ Amadou Lamine Fall1ㅜ, Ousmane Ndiaye ${ }^{1}$
}

\author{
${ }^{1}$ Albert Royer National Children Hospital Center, Dakar, Senegal \\ ${ }^{2}$ La Paix Hospital, Ziguinchor, Senegal \\ ${ }^{3}$ Pediatric Ward, University Hospital Center of Pikine, Dakar, Senegal \\ ${ }^{4}$ Pediatric Ward, University Hospital Center of Abass Ndao, Dakar, Senegal \\ ${ }^{5}$ Pediatric Ward, University Hospital Center of Aristide Le Dantec, Dakar, Senegal \\ Email: ^drniangbacar@gmail.com
}

How to cite this paper: Niang, B., Thiam, L., Ly, F., Dème Ly, I., Boiro, D., Sow, A., Thiongane, A., Ndongo, A.A., Mbaye, A., Keita, Y., Ba, A., Ba, I.D., Dieng, Y.J., Cissé, D.F., Faye, P.M., Fall, A.L. and Ndiaye, O. (2019) Evolutionary Profile of Graves' Disease in Children at Albert Royer National Children Hospital in Dakar. Open Journal of Pediatrics, 9, 119-125.

https://doi.org/10.4236/ojped.2019.92012

Received: March 12, 2019

Accepted: May 6, 2019

Published: May 9, 2019

Copyright (c) 2019 by author(s) and Scientific Research Publishing Inc. This work is licensed under the Creative Commons Attribution International License (CC BY 4.0).

http://creativecommons.org/licenses/by/4.0/

\section{c) (i) Open Access}

\begin{abstract}
Graves' disease is the most common cause of hyperthyroidism. Adequate management is an area of controversy, especially when it comes to children. The objective of our study was to assess the outcome of Graves' disease treatment in Albert Royer Children Hospital of Dakar. This was a retrospective study conducted from 2001 to 2015, and which involved all children between 0 to 15 years of age who were being monitored in the Albert Royer National Children Hospital. The evolutionary modalities were: stability, remission, failure, relapse, lost to follow-up and death. The data were analyzed with SPSS software version 20.0. For the comparisons, the KHI 2 or Fisher test was used with a significance threshold $(\mathrm{p}<0.05)$. During the study period, 88 children were enrolled. The average age was 8.6 years [ranging from 8 months to 15 years]. The consultation delay was 11.36 months. In our study, $61.4 \%$ of the patients were regular in the follow-up, the observance was good in $40.9 \%$ of the cases and 19 patients (21.6\%) were lost to follow-up. Clinical courses of 69 children after treatment with Carbimazole for 37 months were promising in 21 cases $(30.43 \%)$, with 17 cases of remission $(24.63 \%)$ and 4 cases of stability (5.8\%). Age older than 10, the initial ATD dose greater than $1 \mathrm{mg} / \mathrm{kg} /$ day and the initial free T4 lower than $50 \mathrm{pmol} / \mathrm{l}$ were significantly associated with remission with a p value of $0.01 ; 0.024$ and 0.004 .
\end{abstract}

\section{Keywords}

Graves' Disease, Child, Antithyroid Drug, Remission, Senegal 


\section{Introduction}

Hyperthyroidism is a set of disorders related to the excess of thyroid hormones in the target tissues [1]. It is a rare disorder in childhood and represents only $1 \%$ $-5 \%$ of all patients [2].

Despite its relatively low incidence in the pediatric population, Graves' disease (GD) is the predominant cause of hyperthyroidism in childhood [3]. Its incidence progressively increases throughout childhood (very rare under the age of 5 y), with a peak incidence between 11 and $15 \mathrm{y}$ of age. Girls are more commonly affected than boys, with a female/male ratio of 3.5 - 6.1/1 [2] [4]. Treatment of hyperthyroidism in children and adolescents is subject to controversy because none of the therapeutic options is capable of achieving remission in all patients without complications [2]. None of them is directed towards the underlying immunological problem, and reliable predictive factors for remission remain to be defined.

GD in children and adolescents should be considered a specific entity, different from GD of adult onset. Pediatric patients are more refractory to medical treatment and require long-term protocols to achieve remission. Study conducted by J Leger showed that overall estimated remission rate 18 months after the withdrawal of ATD treatment increased with time and was $20 \%, 37 \%, 45 \%$, and $49 \%$ after $4,6,8$, and 10 years follow-up, respectively [5].

The aim of our study was to assess the outcome of the treatment of children at the Albert Royer Children's Hospital Center (CHNEAR).

\section{Methodology}

This was a retrospective, descriptive and analytical study conducted in the Endocrinology Department of CHNEAR in Dakar, which is a reference pediatric hospital in the Senegalese Health Pyramid. The work was carried out during the period January 1, 2001 to December 31, 2015 (15 years). All children with Graves' disease (GD) below 15 years of age at the time of the diagnosis and who were monitored at the clinic for at least 2 years were included. Graves' disease was characterized by a thyrotoxicosis syndrome associated with a vascular diffuse goiter (clinic and/or ultrasond) a Graves' orbitopathy. Sociodemographic, clinical, biological (T3L, T4L and TSHUS at baseline and every 3 months), cervical ultrasound as well as therapeutic and evolutionary data were examined. The evolutionary modalities were as follows: stability (euthyroidism on 2 consecutive appointments), remission (persistent stability after 2 consecutive controls), failure (absence of remission after 24 months of follow-up), relapse (recurrence of hyperthyroidism after remission), lost to follow-up (patient without news having missed at least two appointments) and death. Carbimazole was the treatment for all patients. The treatment regimens were: Scheme A (titration method) and Scheme B (blocking and substitution method). The evolution was considered as favorable in the case of remission or stability and unfavorable in the opposite case. The data was analyzed with SPSS software version 20.0. For 
the comparisons, the KHI 2 or Fisher test were used with a significance threshold $(\mathrm{p}<0.05)$.

\section{Results}

During the study period, 93 children were followed for hyperthyroidism with a hospital frequency of $1.4 \%$. Among them, 88 (i.e. $94.62 \%$ of the cases) were GD patients. The mean age was $8.6 \pm 3.6$ years [Range 0.6 - 15 years]. Children under 5 years old accounted for $25 \%$ of the cases and adolescents for $35 \%$. The sex ratio (boys/girls) was 0.39 . A family history of dysthyroidism was found in 22 patients (25\%). A triggering factor was found in 17 patients (19.3\%) and this was separation with parents $(5.7 \%)$, divorce $(4.5 \%)$ or the death of a loved one (4.5\%). The average consultation time was $11.36 \pm 4.3$ months [range $1-60$ months]. The clinical manifestations are reported in Table 1. In our series, $52.3 \%$ of the patients were thin and $15.9 \%$ were tall. Biologically, the diagnosis was made by the T3L + T4L + TSH trial in 59 cases $(67.1 \%)$, T4L + TSH in 28 cases $(31.8 \%)$ and T4L in 1case (1.1\%). TSH was lowered with T4L and/or T3L increased in $93.2 \%$ of the cases. All patients had received ATD-based medical therapy with or without beta blocker (Figure 1). The doses used are reported in Table 2. In our series, $61.4 \%$ of the patients were regular in the follow-up and the observance was good in $40.9 \%$ of the cases. However, 19 patients (21.6\%) were lost to follow-up. For the 69 patients followed for an average duration of 37 \pm 14.35 months, the evolution was favorable in 21 cases (30.44\%): 17 cases of remission (24.64\%) and 4 cases of stability (5.8\%). Therapeutic failure beyond 24 months was found in $69.56 \%$ cases (48 children). Among them, 6 underwent thyroidectomy. Above 10 years old, the initial ATD dose higher than 1 $\mathrm{mg} / \mathrm{kg} /$ day and the initial free T4 lower than $50 \mathrm{pmol} / \mathrm{l}$ were significantly associated with remission with a $\mathrm{P}$ value of $0.01,0.024$ and 0.004 . The analytical study was reported in Table 3.

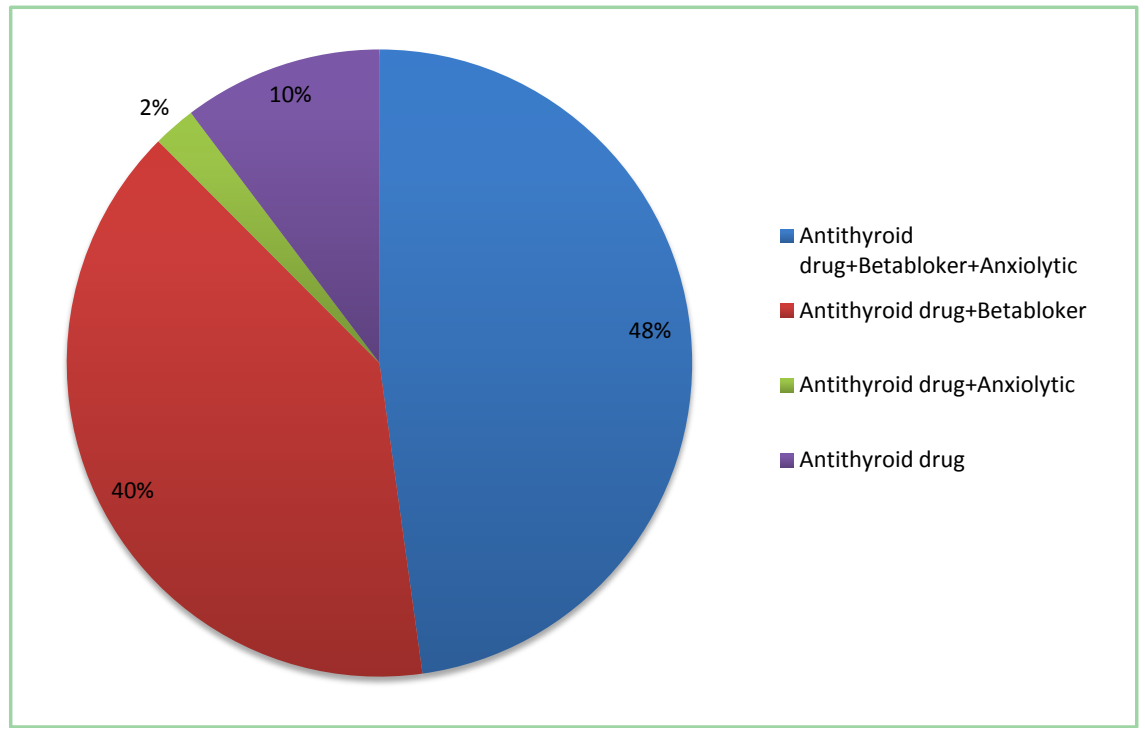

Figure 1. Distribution of patients according to modalities of medical treatment. 
Table 1. Distribution of patients according to clinical signs.

\begin{tabular}{|c|c|c|}
\hline Complaints & Number & Percentage \\
\hline Weigh lost & 55 & $62.5 \%$ \\
\hline Asthenia & 49 & $55.7 \%$ \\
\hline Tremors & 37 & $42 \%$ \\
\hline Irritability & 33 & $37.5 \%$ \\
\hline Palpitation & 32 & $36.4 \%$ \\
\hline Excessive sweating & 31 & $35.2 \%$ \\
\hline Nervosity & 30 & $34.1 \%$ \\
\hline Enuresia & 28 & $31.8 \%$ \\
\hline Diarrhea motrice & 24 & $27.3 \%$ \\
\hline Dyspnea & 20 & $22.7 \%$ \\
\hline Polyphagia & 14 & $15.9 \%$ \\
\hline Insomnia & 11 & $12.5 \%$ \\
\hline Heat intolerance & 10 & $11.4 \%$ \\
\hline Anxiety & 10 & $11.4 \%$ \\
\hline Physical signs & Number & Percentage \\
\hline Tachycardia & 88 & $100(\%)$ \\
\hline Goiter & 76 & $86.4(\%)$ \\
\hline Exophtalmia & 76 & $86.4(\%)$ \\
\hline Sweaty palms & 31 & $35.2(\%)$ \\
\hline Thyroïd thrill & 29 & $33(\%)$ \\
\hline Tabouret sign & 3 & $3.4(\%)$ \\
\hline Melanodermia & 2 & $2.2(\%)$ \\
\hline
\end{tabular}

The commonest complaints at the diagnosis were weight lost, asthenia, tremor, irritability and palpitation. Physical examination found tachycardia, goiter and exophtalmia in 100\%, $86.4 \%$ and $86.4 \%$ respectively.

Table 2. Distribution of patients according to treatment.

\begin{tabular}{cccc}
\hline & Initial dose & Number & Percentage \\
\hline$<1 \mathrm{mg} / \mathrm{Kg} /$ day & 40 & $45.4 \%$ \\
Medical treatment & $1-2 \mathrm{mg} / \mathrm{Kg} /$ day & 46 & $52.3 \%$ \\
& $>2 \mathrm{mg} / \mathrm{Kg} /$ day & 2 & $2.3 \%$ \\
Surgery & - & 6 & $6.8 \%$ \\
\hline
\end{tabular}


Table 3. Analytical statistics.

\begin{tabular}{|c|c|c|c|c|}
\hline \multirow{2}{*}{ Variables } & \multicolumn{3}{|c|}{ Favorable outcome } & \multirow{2}{*}{ Statistical tests } \\
\hline & & Yes & No & \\
\hline \multirow{2}{*}{$\operatorname{Sex}(N=69)$} & Girls & $15(31.25 \%)$ & $33(58.75 \%)$ & \multirow{2}{*}{$\begin{array}{c}\mathrm{P}=0.874 \\
\mathrm{OR}_{95 \%}=1.14[0.42-4.07]\end{array}$} \\
\hline & Boys & $6(28.57 \%)$ & $15(71.43 \%)$ & \\
\hline \multirow{2}{*}{$\begin{array}{l}\text { Age (years) } \\
(\mathrm{N}=69)\end{array}$} & $>10$ & $12(66.67 \%)$ & $6(33.33 \%)$ & \multirow{2}{*}{$\begin{array}{c}P=0.001 \\
\mathrm{OR}_{95 \%}=9.93[2.4-8.43]\end{array}$} \\
\hline & $<10$ & $9(17.65 \%)$ & $42(82.35 \%)$ & \\
\hline \multirow{2}{*}{$\begin{array}{l}\text { Consultation time (months) } \\
\qquad(\mathrm{N}=69)\end{array}$} & $>6$ & $13(33.33 \%)$ & $26(66.67 \%)$ & \multirow{2}{*}{$\begin{array}{c}\mathrm{P}=0.57 \\
\mathrm{OR}_{95 \%}=1.38[0.43-4.47]\end{array}$} \\
\hline & $<6$ & $8(26.67 \%)$ & $22(73.33 \%)$ & \\
\hline \multirow{2}{*}{$\begin{array}{l}\text { Initial dose of ATD }(\mathrm{mg} / \mathrm{kg} / \mathrm{d}) \text { : } \\
\qquad(\mathrm{N}=69)\end{array}$} & $>1$ & $15(48.38 \%)$ & $16(51.61 \%)$ & \multirow{2}{*}{$\begin{array}{c}\mathbf{P}=\mathbf{0 . 0 2 4} \\
\mathrm{OR}_{95 \%}=2.71[1.84-8.95]\end{array}$} \\
\hline & $<1$ & $6(15.79 \%)$ & $32(84.21 \%)$ & \\
\hline \multirow{2}{*}{$\begin{array}{l}\text { Volume of goiter } \\
\qquad(\mathrm{N}=68)\end{array}$} & Grade 2 & $13(30.95 \%)$ & $29(69.05 \%)$ & \multirow{2}{*}{$\begin{array}{c}\mathrm{P}=0.98 \\
\mathrm{OR}_{95 \%}=1.01[0.31-3.32]\end{array}$} \\
\hline & Grade 0 - 1 & $8(30.77 \%)$ & $18(60.23 \%)$ & \\
\hline \multirow{2}{*}{$\begin{array}{l}\text { Protocol used } \\
\qquad(\mathrm{N}=69)\end{array}$} & Protocol A & $14(30.95 \%)$ & $28(69.05 \%)$ & \multirow{2}{*}{$\begin{array}{c}\mathrm{P}=0.818 \\
\mathrm{OR}_{95 \%}=1.14[0.31-3.32]\end{array}$} \\
\hline & Protocol B & $7(25.93)$ & $20(74.07)$ & \\
\hline \multirow{2}{*}{$\begin{array}{l}\text { Initial FT4 value }(\mathrm{pmol} / \mathrm{l}) \\
\qquad(\mathrm{N}=69)\end{array}$} & $>50$ & $5(13.16 \%)$ & $33(86.84 \%)$ & \multirow{2}{*}{$\begin{array}{c}\mathbf{P}=\mathbf{0 . 0 0 4} \\
\mathrm{OR}_{95 \%}=0.14[0.04-0.52]\end{array}$} \\
\hline & $<50$ & $16(51.61 \%)$ & $15(48.39 \%)$ & \\
\hline
\end{tabular}

Age older than 10 years, initial dose of ATD $>1 \mathrm{mg} / \mathrm{kg} / \mathrm{d}$ initial free T4 value $<50 \mathrm{pmol} / \mathrm{l}$ were significantly associated favorable outcome with $\mathrm{p}$ value of $0.001,0.024$ and 0.004 respectively.

\section{Discussion}

The low hospital prevalence of hyperthyroidism in our study $(1.4 \%)$ can be explained by the fact that some patients are still referred to the adult endocrinology clinic. Graves' disease remains the most common etiology of hyperthyroidism, which is widely described in the literature [6] [7]. The average age of our children was young (8.6 years), contrary to data from the literature where hyperthyroidism is the preserve of adolescents. In Africa, studies had average ages of 10, 12.5 and 13.2 [2] [6] [8]. The early diagnosis in our study was due to the improvement of the technical platform and the development of pediatric endocrinology. In our study, an increase in stature was noted only in $15.9 \%$ of the cases, whereas in the literature it is recorded in $3 / 4$ of the cases [9]. This may be related to either pre-existing chronic malnutrition, which is common in our developing countries, or to a prolonged course of the disease. The majority of patients had cervical ultrasound on inclusion. Indeed, thyroid ultrasound remains crucial in the diagnostic, therapeutic and surveillance strategy of thyroid diseases [10]. Its non-invasive, non-irradiating and inexpensive nature certainly favored its current use, as the first examination carried out in association with the hormonal trial as part of the thyroid checkup. The antithyroid drug used as first-line treatment was carbimazole as advocated by some authors [11] [12]. In Europe, it is carbimazole and methimazole that are the preferred treatment for hyperthyroidism in children, while in the United States PTU is the reference [13]. Both 
protocols for the treatment of hyperthyroidism have been used in our patients. They did not give statistically different results. After a mean follow-up time of 37 months, the remission rate was $24.64 \%$. The remission rate was estimated by several studies in children between $20 \%$ and $30 \%$ following ATD medical treatment during two years or more [14] [15]. In our study, the factors associated with remission were age and high dose of ATD. Thus, remission was significantly greater in the age group of patients above 10. An American study yielded similar results showing the relationship between age and response to ATD [16]. The low rate of recurrence can be attributed in part to the long duration of treatment in our children. Indeed, the risk of relapse was also reduced by a prolonged duration of medical treatment, a reduction of $43 \%$ every 12 months of additional treatment with ATD [5].

The lost to follow up rate can be explained in our context by the problem of poverty and inaccessibility to care. The failure rate of medical treatment in our study (69.56\%) is high compared to that recorded in India (52.4\%) [11]. This would be linked in our context to a multitude of difficulties including: the high cost of drugs, the unavailability of ATD, and the use of traditional medicine. All these difficulties are at the origin of therapeutic ruptures, even abandonments, hence a more and more prominent place given to radical treatment including surgery [17].

\section{Conclusion}

Longer duration of ATD treatment seems to increase the remission rate in our GD patients. It is also essential to expand the indications for surgery and also to promote the development of treatment with radioactive iodine.

\section{Conflicts of Interest}

The authors declare no conflicts of interest regarding the publication of this paper.

\section{References}

[1] Toublanc, J.-E. (2008) Pathologie thyroïdienne de l'enfant (hypothyroïdie, hyperthyroïdie et cancer). EMC-Pédiatrie-Maladies infectieuses, 2, 1-11. https://doi.org/10.1016/S1637-5017(07)72389-X

[2] Kraiem, Z. and Newfield, R.S. (2001) Graves' Disease in Childhood. Journal of Pediatric Endocrinology and Metabolism, 14, 229-243. https://doi.org/10.1515/JPEM.2001.14.3.229

[3] LaFranchi, S. and Mandel, S. (1996) Graves' Disease and Otherforms of Hyperthyroidism in Infants and Children. Current Opinion in Endocrinology and Diabetes, 3, 101-109. https://doi.org/10.1097/00060793-199604000-00005

[4] Gruiieiro-Papendieck, L., Chiesa, A., Finkielstain, G. and Heinrich, J.J. (2003) Pediatric Graves' Disease: Outcome and Treatment. Journal of Pediatric Endocrinology and Metabolism, 16, 1249-1255.

https://doi.org/10.1515/JPEM.2003.16.9.1249 
[5] Leger, et al. (2012) Long-Term Outcome in Pediatric Graves' Disease. The Journal of Clinical Endocrinology \& Metabolism, 97, 110-119. https://doi.org/10.1210/jc.2011-1944

[6] Sidibé, A.T., Dembélé, M., Diarra, A.S. and Bocoum, A.I. (2007) Hyperthyroidie chez l'enfant: Experience d'un service de medecine interne au Mali. Annales d Endocrinologie, 68, 177-180. https://doi.org/10.1016/j.ando.2007.05.003

[7] Williamson, S. and Greene, S.A. (2010) Incidence of Thyrotoxicosis in Childhood: A National Population Based Study in the UK and Ireland. Clinical Endocrinology, 72, 358-363. https://doi.org/10.1111/j.1365-2265.2009.03717.x

[8] Rezgani Chelbi, I., Meddeb, I., Yeddeas, I. and Limam, K. (2016) La maladie de Basedow chez l'enfant: Placede l'irathérapie; SFE Bordeaux 2016. Annales d Endocrinologie, 77, 372-412. https://doi.org/10.1016/j.ando.2016.07.455

[9] Meziani, N., Takbou, N., Fedala, S. and Chentli, F. (2002) L'hyperthyroïdie de l'enfant. Ann Endocrinology, 63, 364.

[10] Tramalloni, J. and Monpeyssen, H. (2003) Echographie de la thyroïde. Encycl Méd Chir, Paris, 32-700-A-20.

[11] Bhadada, S., Bhansali, A., Velayuthain, P. and Nasoodi, S.R. (2006) Juvenile Hyperthyroidism: An Experience. Indian Pediatrics, 43, 301-307.

[12] Luton, J.P., Vidal-trecan, G., Guillaume, B., Blondeau, P. and Baulieu, J.L. (1984) Les hyperthyroïdies: Etude thérapeutique. Encycl Med Chir, Paris, Glandes Endocrines Nutrition, 10003 A40, 9, 14 p.

[13] Davies, T.F. and Larsen, P.R. (2003) Thyrotoxicosis. In: Larsen, P.R., Kronenberg, H.M., Melmed, D. and Polonsky, K.S., Eds., Williams Textbook of Edocrinology, 10th Edition, W. B. Saunders, Philadelphia, 374-414.

[14] Rivkees, S.A. (2014) Maladie de Graves pédiatrique: Gestion dans l'ère post-propylthiouracile. International Journal of Pediatric Endocrinology, 2014, 10. https://doi.org/10.1186/1687-9856-2014-10

[15] Hamburger, J.I. (1985) Prise en charge de l'hyperthyroïdie chez l'enfant et l'adolescent. The Journal of Clinical Endocrinology \& Metabolism, 60, 1019-1024. https://doi.org/10.1210/jcem-60-5-1019

[16] Schulman, D.I., Muhar, I., Jorgensen, E.V., Diamond, F.B., Bercu, B.B. and Root, A.W. (1997) Autoimmune Hyperthyroidism in Prepubertal Children and Adolescents: Comparison of Clinical and Biochemical Features at Diagnosis and Responses to Medical Therapy. Thyroid, 7, 755-760. https://doi.org/10.1089/thy.1997.7.755

[17] Schüssler-Fiorenza, C.M., Bruns, C.M. and Chen, H. (2006) The Surgical Management of Graves' Disease. Journal of Surgical Research, 133, 207-214. https://doi.org/10.1016/j.jss.2005.12.014 